\title{
Fatty acids stimulate insulin secretion from human pancreatic islets at fasting glucose concentrations via mitochondria-dependent and -independent mechanisms
}

Jing Cen, Ernest Sargsyan ${ }^{*}$ and Peter Bergsten

\begin{abstract}
Background: Free fatty acids (FFAs) acutely stimulate insulin secretion from pancreatic islets. Conflicting results have been presented regarding this effect at non-stimulatory glucose concentration, however. The aim of our study was to investigate how long-chain FFAs affect insulin secretion from isolated human pancreatic islets in the presence of physiologically fasting glucose concentrations and to explore the contribution of mitochondria to the effects on secretion.

Methods: Insulin secretion from human pancreatic islets was measured from short-term static incubation or perfusion system at fasting glucose concentration $(5.5 \mathrm{mM})$ with or without 4 different FFAs (palmitate, palmitoleate, stearate, and oleate). The contribution of mitochondrial metabolism to the effects of fatty acid-stimulated insulin secretion was explored.

Results: The average increase in insulin secretion, measured from statically incubated and dynamically perifused human islets, was about 2-fold for saturated free fatty acids (SFAs) (palmitate and stearate) and 3-fold for monounsaturated free fatty acids (MUFAs) (palmitoleate and oleate) compared with $5.5 \mathrm{mmol} / \mathrm{l}$ glucose alone. Accordingly, MUFAs induced $50 \%$ and SFAs $20 \%$ higher levels of oxygen consumption compared with islets exposed to $5.5 \mathrm{mmol} /$ I glucose alone. The effect was due to increased glycolysis. When glucose was omitted from the medium, addition of the FFAs did not affect oxygen consumption. However, the FFAs still stimulated insulin secretion from the islets although secretion was more than halved. The mitochondria-independent action was via fatty acid metabolism and FFAR1/GPR40 signaling.
\end{abstract}

Conclusions: The findings suggest that long-chain FFAs acutely induce insulin secretion from human islets at physiologically fasting glucose concentrations, with MUFAs being more potent than SFAs, and that this effect is associated with increased glycolytic flux and mitochondrial respiration.

Keywords: Insulin secretion, Human pancreatic islets, Saturated fatty acids, Monounsaturated fatty acids, Mitochondrial respiration

Abbreviations: ECAR, Extracellular acidification rate; FFA, Free fatty acid; MUFA, Monounsaturated free fatty acid; OA, Oleate; OCR, Oxygen consumption rate; PA, Palmitate; PAO, Palmitoleate; PBS, Phosphate buffer saline; SA, Stearate; SFA, Saturated free fatty acid

\footnotetext{
* Correspondence: ernest.sargsyan@mcb.uu.se

Department of Medical Cell Biology, Uppsala University, Box 571, Uppsala,

Sweden
} 


\section{Background}

Short-term exposure of beta-cells to free fatty acids (FFAs) potentiates glucose-stimulated insulin secretion $[1,2]$. Such potency has been reported to increase with chain length and degree of saturation of the FFAs $[2,3]$. The effect of FFAs on insulin secretion has been related to FFA metabolism [4-6] and to signaling via Gq protein-coupled receptor, FFAR1/GPR40 [7, 8]. Our recent studies demonstrated that in the presence of elevated glucose concentrations rise in insulin secretion is associated with increased mitochondrial function, which in turn is mainly attributed to enhanced glucose oxidation [9].

FFAs of different chain length and degrees of saturation are normal components in the circulation $[10,11]$ and their levels are raised during the fasting state [12]. At low glucose concentrations, FFAs are main substrates for energy production in islets [13, 14]. Whether FFAs affect insulin secretion at fasting glucose levels is not clear. Whereas some groups reported that there is no or little effect of FFAs on insulin secretion [3, 15, 16], others showed that FFAs stimulate insulin secretion at low glucose concentrations $[17,18]$.

In the present study we have addressed how longchain saturated free fatty acids (SFAs) palmitate and stearate and their corresponding mono-unsaturated free fatty acids (MUFAs) palmitoleate and oleate affect insulin secretion from isolated human pancreatic islets at fasting glucose concentrations. These FFAs are four of the most prevalent fatty acids in the circulation [11]. We also explored the role of mitochondrial activity in the action. We found that FFAs acutely increased insulin secretion at fasting glucose concentrations with MUFAs being more potent than SFAs, and that the enhanced insulin secretion was partly associated with the rise in glucose flux and mitochondrial respiration.

\section{Methods}

\section{Human islet culture}

Human islets were obtained from the Nordic Network for Clinical Islet Transplantation (Uppsala University Hospital, Uppsala, Sweden). In total, human islets from 26 brain-dead non-diabetic donors were used in this study (age: $60.1 \pm 2.0$ years, male/female: 14/12; BMI: $27.4 \pm 0.9 \mathrm{~kg} / \mathrm{m}^{2}$, HbA1c: $\left.5.5 \pm 0.1 \%\right)$. Human islets were cultured in CMRL 1066 medium (Invitrogen, Paisley, UK) containing $5.5 \mathrm{mmol} / \mathrm{l}$ glucose (Sigma, St. Louis, MO) and supplemented with $10 \%$ fetal bovine serum (Invitrogen), 1 \% glutamine (Invitrogen), 100 units $/ \mathrm{ml}$ penicillin (Invitrogen) and $100 \mu \mathrm{g} / \mathrm{ml}$ streptomycin (Invitrogen) at $37{ }^{\circ} \mathrm{C}$ in humidified air containing $5 \% \mathrm{CO}_{2}$. Islets were used within 10 days after isolation.

\section{Fatty acid preparation}

Fatty acids were prepared as previously described [19]. Briefly, $100 \mathrm{mmol} / \mathrm{l}$ stock solutions containing palmitate, stearate, or oleate (all from Sigma Aldrich, St. Louis, MO, USA) were prepared by dissolving fatty acids in $50 \%$ ethanol. Stock solution of palmitoleate (Sigma Aldrich) was prepared in $100 \%$ ethanol to a concentration of $200 \mathrm{mmol} / \mathrm{l}$. Stock solutions were then diluted in incubation medium containing $5 \mathrm{mg} / \mathrm{ml}$ of fatty acid-free BSA (Boehringer Mannheim GmbH, Mannheim, Germany) to a final concentration of $0.5 \mathrm{mmol} / \mathrm{l}$. Fatty acids were allowed to complex with BSA at $37^{\circ} \mathrm{C}$ for at least $30 \mathrm{~min}$.

\section{Human islet perifusion and static incubation}

Human islets were perifused as described previously [20]. Briefly, 25-30 human islets were hand-picked and placed into a perifusion chamber. Islets were perifused for $60 \mathrm{~min}$ at $37{ }^{\circ} \mathrm{C}$ in $\mathrm{KRBH}$ buffer consisting of $130 \mathrm{mmol} / \mathrm{l} \mathrm{NaCl}, 4.8 \mathrm{mmol} / \mathrm{l} \mathrm{KCl}, 1.2 \mathrm{mmol} / \mathrm{l} \mathrm{MgSO}$, $1.2 \mathrm{mmol} / \mathrm{l} \mathrm{KH}_{2} \mathrm{PO}_{4}, 1.2 \mathrm{mmol} / \mathrm{l} \mathrm{CaCl}_{2}, 5.0 \mathrm{mmol} / \mathrm{l}$ $\mathrm{NaHCO}_{3}$ and $5.0 \mathrm{mmol} / \mathrm{l} \mathrm{HEPES}$, titrated to $\mathrm{pH} 7.4$ with $\mathrm{NaOH}$ and supplemented with $5 \mathrm{mg} / \mathrm{ml}$ fatty acid-free BSA and $5.5 \mathrm{mmol} / \mathrm{l}$ glucose or without glucose. After this initial perifusion period, samples were collected every $5 \mathrm{~min}$ for $20 \mathrm{~min}$ at the same concentration of glucose. This was followed by another 20-min perifusion with the same buffer containing $5 \mathrm{mg} / \mathrm{ml}$ fatty acid-free BSA and $0.5 \mathrm{mmol} / \mathrm{l}$ palmitate (16:0), palmitoleate $(16: 1)$, stearate $(18: 0)$, or oleate (18:1). In addition, $10 \mu \mathrm{M}$ triacsin C (Sigma Aldrich) or $10 \mu \mathrm{M}$ DC260126 (Tocris Bioscience, Bristol, UK) were added during the perifusion to inhibit long-chain fatty acyl CoA synthetase or FFAR1/GPR40 signaling, respectively. Perifusates were collected at $2,4,6,8,10,15$, and $20 \mathrm{~min}$. The perifusion rate was $170 \mu \mathrm{l} / \mathrm{min}$ and collected perifusates were used to measure the amounts of secreted insulin. Insulin released during the first $6 \mathrm{~min}$ after the introduction of fatty acids was referred to as the first phase and that during the subsequent 14 min was regarded as the second phase.

Human islets were hand-picked in batches of 50 and statically incubated for $60 \mathrm{~min}$ in $0.5 \mathrm{ml} \mathrm{KRBH} \mathrm{buffer}$, identical to the one used for the perifusion, supplemented with $0.5 \mathrm{mmol} / \mathrm{l}$ of the different fatty acids and $5.5 \mathrm{mmol} / \mathrm{l}$ glucose or without glucose for $20 \mathrm{~min}$.

The amount of insulin secreted was measured by enzyme-linked immunosorbent assay as described previously [21]. For each perifusion, total fatty acid-induced insulin secretion was normalized to insulin secretion in the absence of the fatty acids. For static incubation total insulin secretion during $20 \mathrm{~min}$ was normalized to total protein content and insulin secretion was expressed as fold change between insulin secretion from fatty acidtreated and untreated islets for each donor. 
Oxygen consumption and extracellular acidification rates The oxygen consumption rate (OCR) and extracellular acidification rate (ECAR) of isolated human pancreatic islets were determined by Extracellular Flux Analyzer XF ${ }^{\mathrm{e}} 96$ (Seahorse Bioscience, MA, USA) as previously reported [22]. Ten hand-picked human islets were placed into the wells of the $\mathrm{XF}^{\mathrm{e}} 96$ cell culture microplate precoated with poly-D-lysine. Islets were pre-incubated with assay medium (Seahorse Bioscience) composed of $143 \mathrm{mmol} / \mathrm{l} \mathrm{NaCl}, \quad 5.4 \mathrm{mmol} / \mathrm{l} \mathrm{KCl}, 0.91 \mathrm{mmol} / \mathrm{l}$ $\mathrm{NaH}_{2} \mathrm{PO}_{4}, \quad 0.8 \mathrm{mmol} / \mathrm{l} \quad \mathrm{MgSO}_{4}, \quad 1.8 \mathrm{mmol} / \mathrm{l} \quad \mathrm{CaCl}_{2}$, $2 \mathrm{mmol} / \mathrm{l}$ Glutamax, $3 \mathrm{mg} / \mathrm{l}$ Phenol Red, and supplemented with $5 \mathrm{mg} / \mathrm{ml}$ fatty acid-free BSA and $0.5 \mathrm{mmol} /$ 1 palmitate (16:0), palmitoleate (16:1), stearate $(18: 0)$, or oleate $(18: 1)$ in the presence or absence of $5.5 \mathrm{mmol} / \mathrm{l}$ glucose ( $\mathrm{pH}$ adjusted to 7.4) for $1 \mathrm{~h}$ at $37^{\circ} \mathrm{C}$ before the microplate was inserted into the Analyzer. For each donor, 6-8 replicates of each treatment condition were used. OCR and ECAR were then measured in parallel for $40 \mathrm{~min}$ followed by the injection of $5 \mu \mathrm{mol} / \mathrm{l}$ rotenone and $5 \mu \mathrm{mol} / \mathrm{l}$ antimycin $\mathrm{A}$ to inhibit mitochondrial respiration. The remaining OCR was considered as non-mitochondrial respiration. To calculate the mitochondrial respiration, non-mitochondrial OCR was subtracted from the total OCR. Data were normalized to total islet area calculated by the Image J software (National Institutes of Health, USA) from pictures (40x) taken with camera (Olympus) mounted onto an inverted Olympus CKX41 microscope. Calculated basal OCR and ECAR were expressed as fold changes from fatty acid-treated islets compared with that from untreated islets for each experiment.

\section{Protein content}

Human islets were washed with phosphate buffer saline (PBS) (Sigma) and lysed in PBS containing $1 \%$ Triton-X 100 (Sigma). Total protein content in the lysates was determined by DC protein assay according to the manufacturer's instructions (Bio-Rad Laboratories, USA).

\section{Data analysis}

Results were presented as means \pm SEM. Statistical analysis was performed using GraphPad Prism Version 6.0b (GraphPad software, CA, USA). Statistical significance among several groups was analyzed by using one-way ANOVA followed by Holm-Sidak multiple comparison test. $P<0.05$ was considered statistically significant.

\section{Results}

Fatty acids acutely enhance insulin secretion, OCR and ECAR from human islets at fasting glucose concentrations with MUFAs being more potent than SFAs

Insulin secretion rate from statically incubated human islets in the presence of $5.5 \mathrm{mmol} / \mathrm{l}$ glucose was $1.48 \pm$
$0.24 \mathrm{fmol} / \mathrm{min} / \mu \mathrm{g}$ protein. When fatty acids were added to the incubation containing $5.5 \mathrm{mmol} / \mathrm{l}$ glucose, insulin secretion was significantly raised (Fig. 1a). The rise was around 1.5-fold in the presence SFA palmitate (16:0) or stearate (18:0), and significantly higher reaching 2 to 2.5fold when exposed to MUFA palmitoleate (16:1) or oleate $(18: 1)$. Chain length played no significant role in the effects of fatty acids on insulin secretion. The observations that fatty acids stimulated insulin secretion from human islets in the presence of fasting glucose concentration and that MUFAs were more potent than SFAs made us study the secretory response dynamically by perifusing human islets. Perifused human islets secreted insulin at $2.09 \pm 0.12 \mathrm{fmol} / \mathrm{min} / \mu \mathrm{g}$ protein in the presence of $5.5 \mathrm{mmol} / \mathrm{l}$ glucose (Fig. 1b). When SFA palmitate or stearate was acutely added to the perifusion medium insulin release was enhanced equally by approximately 2 -fold by either of the SFAs (Fig. 1b and c). MUFAs were significantly more potent with palmitoleate causing 4-fold and oleate 3-fold rise in insulin secretion (Fig. $1 \mathrm{~b}$ and c). The rises in insulin secretion caused by SFAs and MUFAs (Fig. 1c) were accounted for by rises in both first (Fig. 1d) and second (Fig. 1e) phases of insulin secretion.

To examine the contribution of mitochondrial metabolism to the effects of SFAs and MUFAs on insulin secretion, mitochondrial OCR during the fatty acid treatment was determined. In the presence of $5.5 \mathrm{mmol} /$ 1 glucose OCR in human islets was $502 \pm 24 \mathrm{pmol} / \mathrm{min} /$ $\mathrm{mm}^{2}$. The fatty acids significantly elevated OCR with MUFAs being more potent than SFAs (Fig. 2a and b), which was in line with the insulin secretion results (Fig. 1). Whereas SFAs caused 1.2-fold rise in OCR, MUFAs had significantly higher 1.4-fold rise in OCR in human islets.

The contribution of glycolytic flux to the observed changes induced by SFAs and MUFAs on OCR was next examined by measuring ECAR. In the presence of $5.5 \mathrm{mmol} / \mathrm{l}$ glucose ECAR in human islets was $99 \pm 13$ $\mathrm{mpH} / \mathrm{min} / \mathrm{mm}^{2}$. When SFA palmitate or stearate was added, ECAR significantly increased 1.3-fold (Fig. 2c). Further significant rise in ECAR to 1.6-fold was observed, when islets were exposed to MUFA palmitoleate or oleate.

The results suggest that FFAs trigger insulin secretion and enhance mitochondrial respiration in beta-cells with MUFAs more potently than SFAs, and that enhanced glycolysis contributes to these events.

Fatty acids acutely enhance insulin secretion but not OCR and ECAR from human islets in the absence of glucose with MUFAs being more potent than SFAs

To further address the contribution of glycolysis in FFAinduced insulin secretion and rise in OCR, human islets 

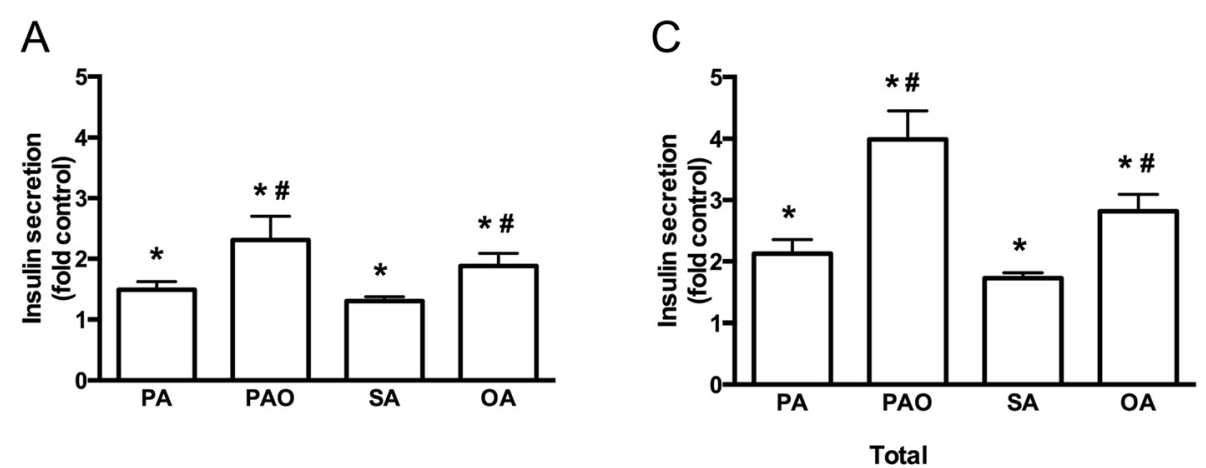

D
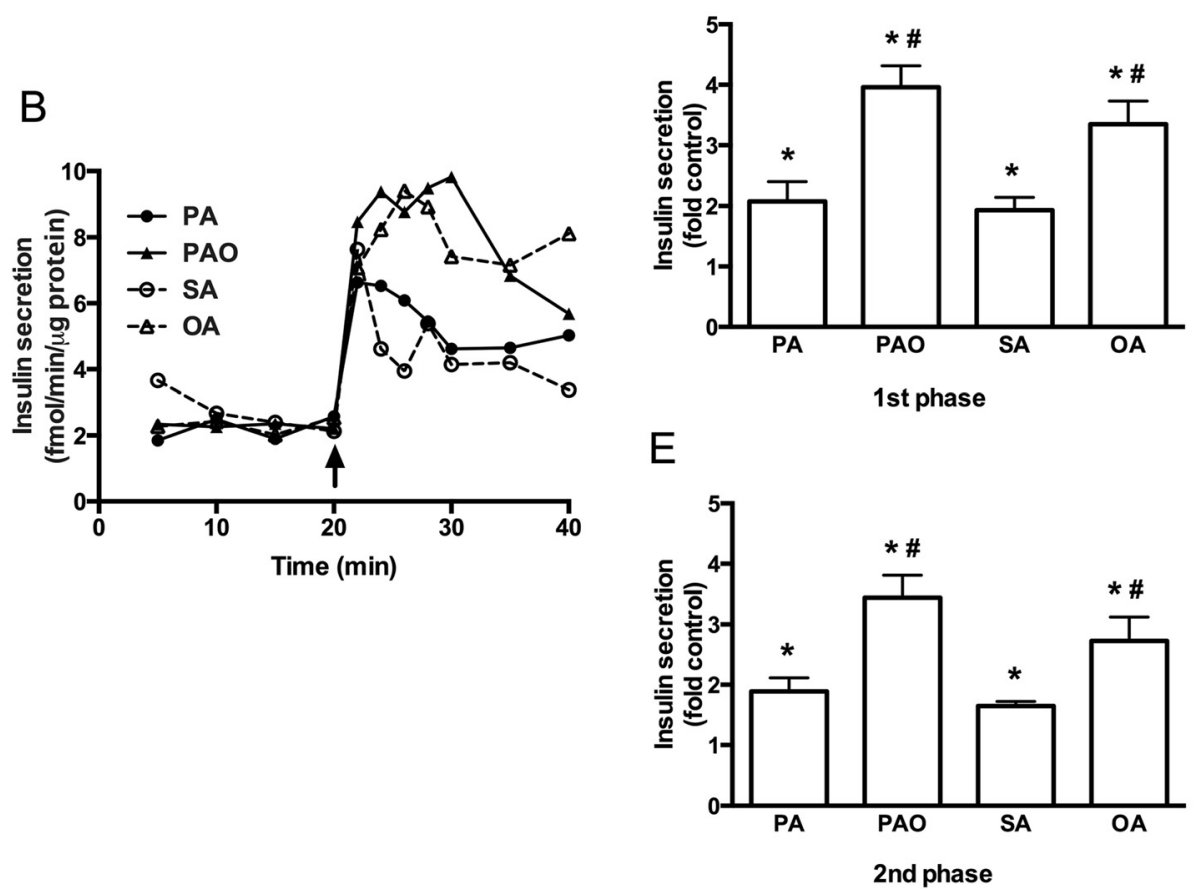

Fig. 1 Acute effects of free fatty acids on insulin secretion at $5.5 \mathrm{mmol} / \mathrm{l}$ glucose. Human islets were incubated at $5.5 \mathrm{mmol} / \mathrm{l}$ glucose in the presence or absence of $0.5 \mathrm{mM}$ palmitate $(\mathrm{PA})$, palmitoleate $(\mathrm{PAO})$, stearate $(\mathrm{SA})$, or oleate $(\mathrm{OA})$ for $20 \mathrm{~min}$. a Insulin secretion from statically incubated human islets was expressed as fold secretion at control. $\mathbf{b}$ Representative graph of dynamic insulin secretion from perifused islets is shown. Fatty acids were added as indicated. c-e Total, first-phase, and second-phase of fatty acid-stimulated insulin secretion during perifusion was expressed as fold control. Results are means \pm SEM of 8 donors. ${ }^{*} P<0.05$ vs Control, $\# P<0.05$ PA vs PAO or SA vs OA

were exposed to the SFA (palmitate or stearate) or MUFA (palmitoleate or oleate) in the absence of glucose. In the absence of glucose and prior to introducing the FFAs, ECAR in the islets was $61 \pm 3 \mathrm{mpH} / \mathrm{min} / \mathrm{mm}^{2}$, which was $60 \%$ of that observed in islets incubated in the presence of $5.5 \mathrm{mmol} / \mathrm{l}$ glucose. As expected ECAR was not affected when SFA (palmitate or stearate) or MUFA (palmitoleate or oleate) was added to islets incubated in the absence of glucose (Fig. 3a). When incubating islets in the absence of glucose, OCR was reduced to $440 \pm 25 \mathrm{pmol} / \mathrm{min} / \mathrm{mm}^{2}$, representing $88 \%$ of OCR levels observed in islets incubated in the presence of $5.5 \mathrm{mmol} / \mathrm{l}$ glucose. Neither inclusion of the SFAs nor MUFAs caused any change in mitochondrial respiration in these islets maintained in the absence of glucose (Fig. $3 \mathrm{~b}$ and $\mathrm{c}$ ). These results confirm the role of glucose in FFA-induced elevation of mitochondrial metabolism.

Insulin secretion rate from statically incubated human islets in the absence of glucose was $0.59 \pm 0.14 \mathrm{fmol} /$ $\mathrm{min} / \mu \mathrm{g}$ protein, which was $40 \%$ of the secretion rate at $5.5 \mathrm{mmol} / \mathrm{l}$ glucose. When SFAs or MUFAs were included, insulin release was significantly increased with the MUFAs being more potent than the SFAs (Fig. 4a). The fold changes were approximately the same as for islets incubated in the presence of $5.5 \mathrm{mmol} / \mathrm{l}$ glucose. Dynamic insulin release was also measured by perifusing human islets in the absence of glucose. Perifused human 


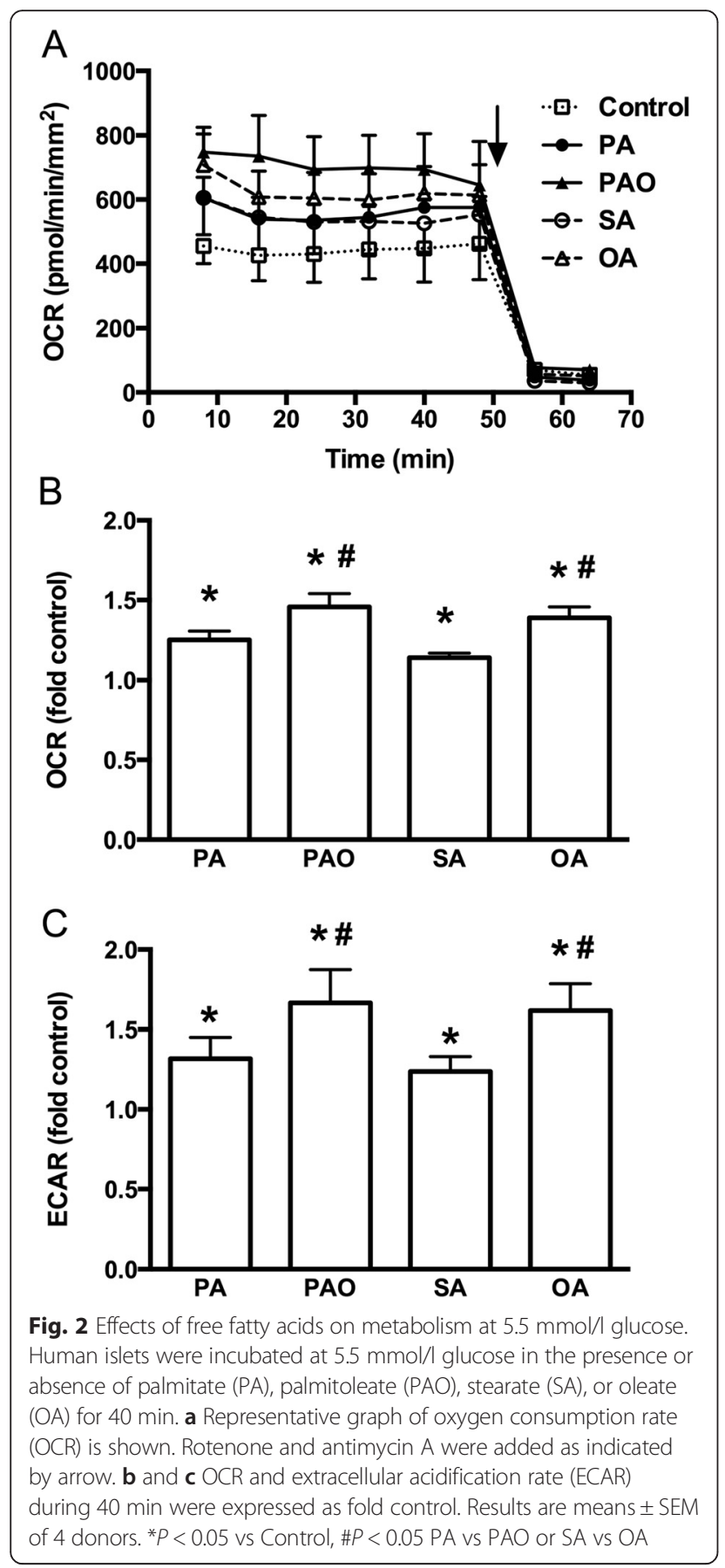

islets secreted insulin at $0.99 \pm 0.10 \mathrm{fmol} / \mathrm{min} / \mu \mathrm{g}$ protein in the absence of glucose, which was $50 \%$ of that in presence of $5.5 \mathrm{mmol} / \mathrm{l}$ glucose. Similar to the static incubation insulin release was enhanced by both the SFAs and the MUFAs with the MUFAs being more potent than the SFAs (Fig. 4b and c). Again, fold changes were similar to those observed from islets perifused in the presence of $5.5 \mathrm{mmol} / \mathrm{l}$ glucose. The increase in insulin secretion was due to rise in both first and second phases of insulin secretion (Fig. $4 \mathrm{~d}$ and e). The results show that
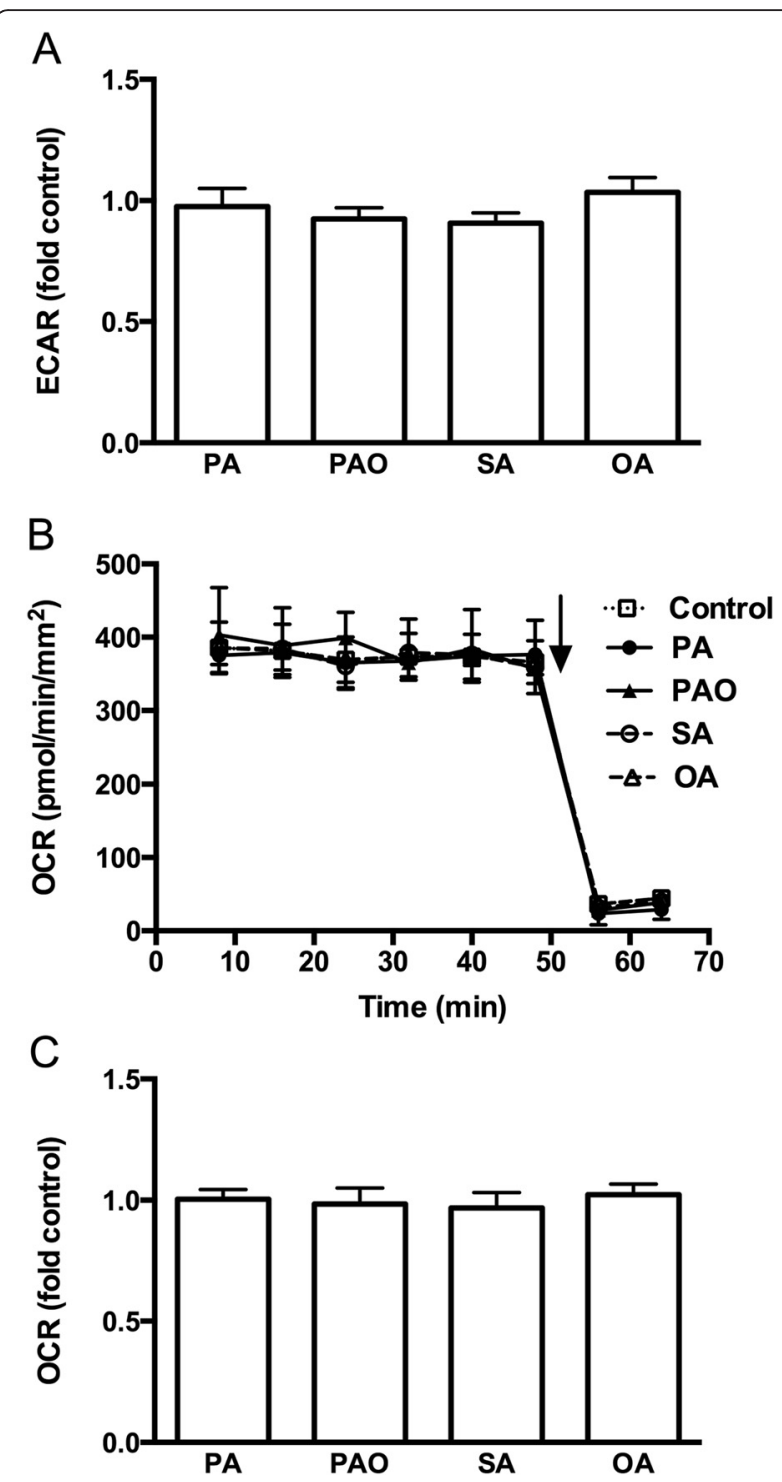

Fig. 3 Effects of free fatty acids on metabolism in the absence of glucose. Human islets were incubated with or without palmitate (PA), palmitoleate (PAO), stearate (SA), or oleate (OA) for $40 \mathrm{~min}$ in the absence of glucose. a Extracellular acidification rate (ECAR) was expressed as fold control. b Representative graph of oxygen consumption rate (OCR) is shown. Rotenone and antimycin A were added as indicated by arrow. c OCR was expressed as fold control. Results are means \pm SEM of 4 donors

FFAs are capable of enhancing insulin secretion via mitochondria-independent mechanisms.

Intracellular metabolism of fatty acids and GPR40/FFAR1 signaling are involved in the stimulation of insulin secretion by fatty acids in the absence of glucose To examine what are the mechanisms of mitochondriaindependent action of fatty acids on insulin secretion, we inhibited intracellular metabolism of fatty acids and FFAR1/GPR40 signaling with long-chain fatty acyl CoA 
A

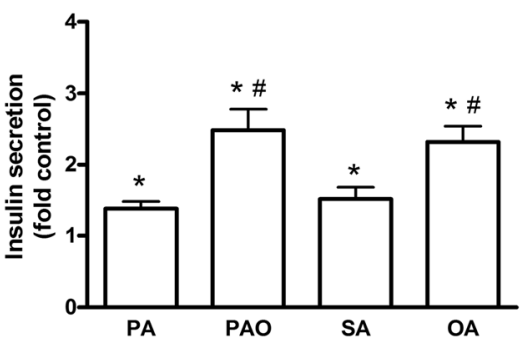

B

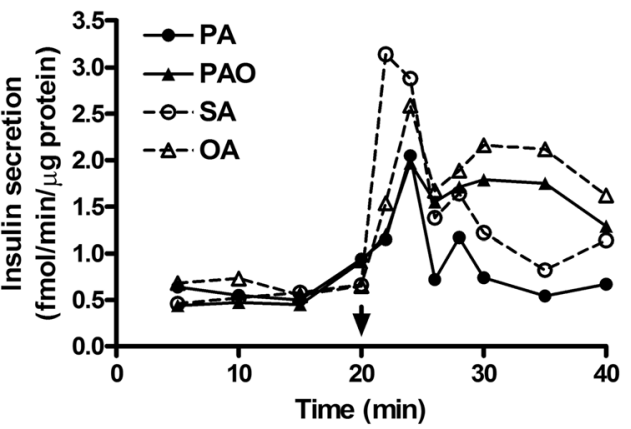

C

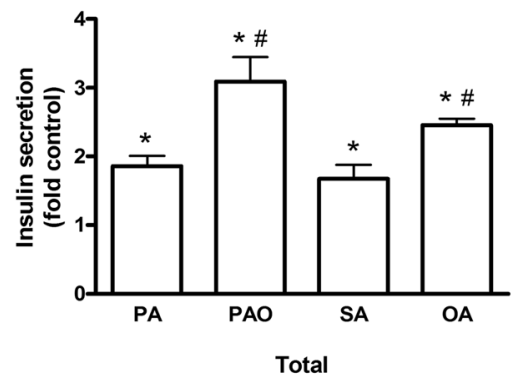

D

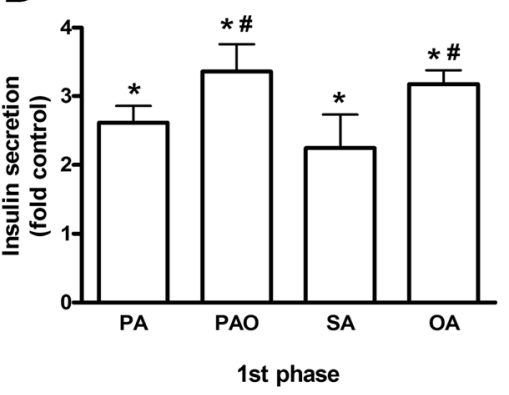

E

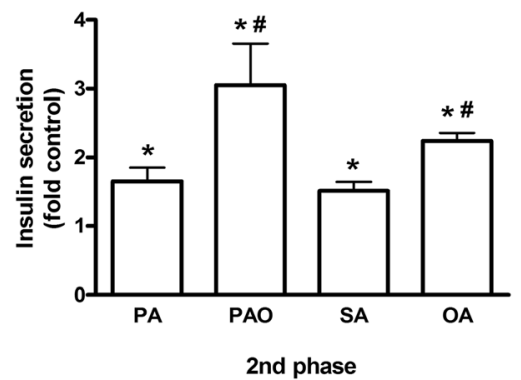

Fig. 4 Acute effects of free fatty acids on insulin secretion in the absence of glucose. Human islets were incubated with or without palmitate (PA), palmitoleate (PAO), stearate (SA), or oleate (OA) for 20 min in the absence of glucose. a Insulin secretion from statically incubated human islets was expressed as fold secretion at control. $\mathbf{b}$ Representative graph of dynamic insulin secretion from perifused islets is shown. Fatty acids were added as indicated. c-e Total, first-phase, and second-phase of fatty acid-stimulated insulin secretion during perifusion was expressed as fold control. Results are means \pm SEM of 8 donors. ${ }^{*} P<0.05$ vs control, \#P<0.05 PA vs PAO or SA vs OA

synthetase inhibitor triascin $\mathrm{C}$ and FFAR1/GPR40 inhibitor DC260126, respectively. Both inhibitors prevented palmitate-induced elevation of insulin secretion (Fig. 5a and b). The inhibitory effects of triacsin C and DC260126 on insulin secretion were also detected in oleate-treated human islets (Fig. 5e and f). The changes in insulin secretion were due to decrease in first and second phases of insulin secretion (Fig. 5c, d, g and h).

\section{Discussion}

FFA concentrations vary widely in the circulation from hour to hour [12]. Such fluctuations take place both at high and low glucose concentrations [23]. It is generally accepted that fatty acids potentiate insulin secretion at high glucose concentrations [2, 3, 5, 16, 17]. Our study shows that fatty acids enhance insulin secretion even at low glucose concentrations. Similar to glucose, fatty acids stimulated biphasic insulin secretion [18].

In our study, MUFAs were more potent in inducing insulin secretion than SFAs, which is in contrast to previous studies [2]. In an attempt to explore the mechanisms behind the different levels of secreted insulin stimulated by different fatty acids we examined mitochondrial activity after the treatment. Mitochondrial metabolism of beta-cells is known to play a key role in maintaining nutrient-induced insulin secretion [24]. It has been demonstrated that at high glucose concentrations palmitate enhances mitochondrial function by increasing glucose oxidation [9]. In the present study we extended this observation by comparing the effects of 

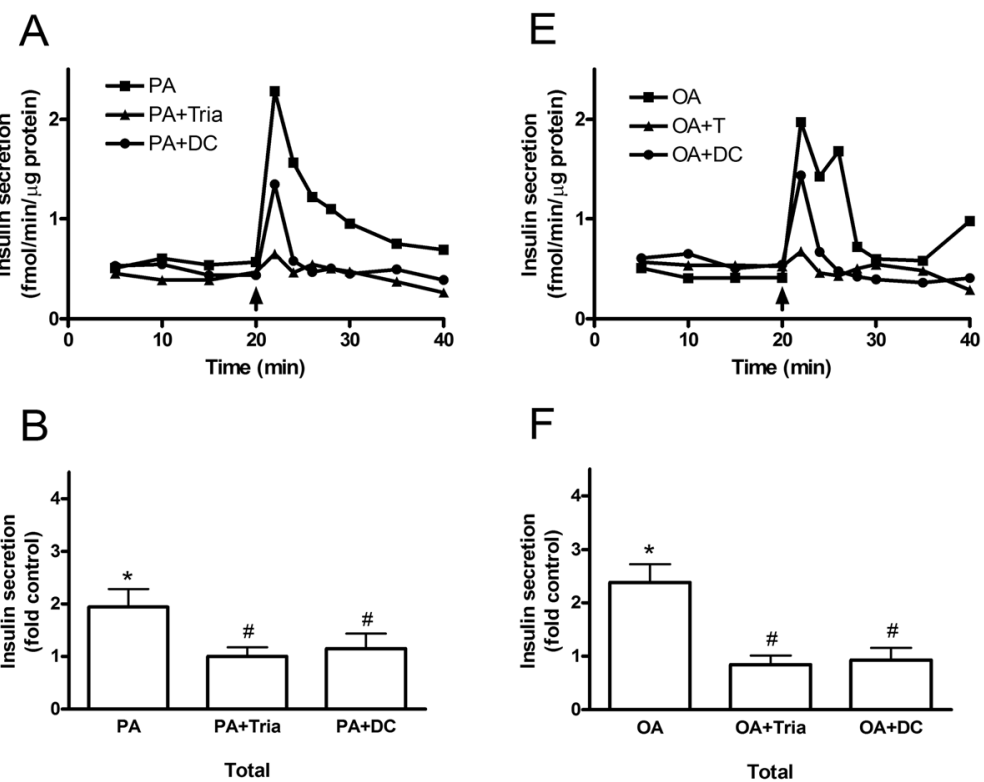

$\mathrm{F}$

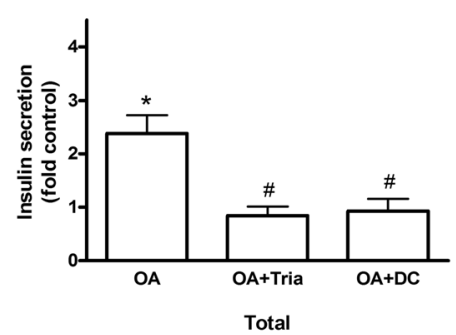

C

G
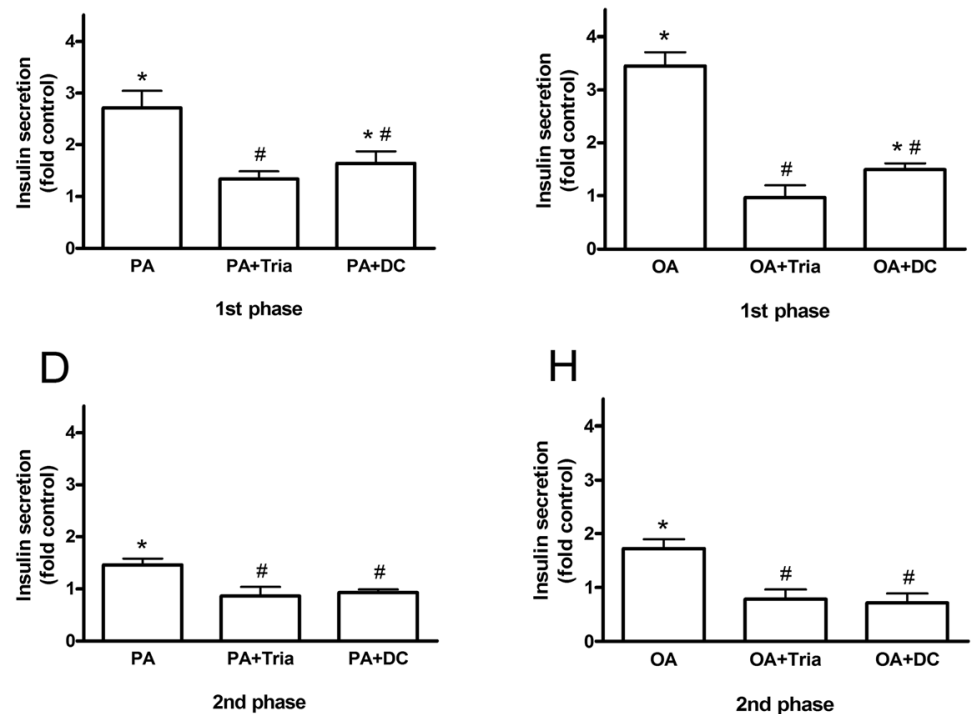

Fig. 5 Contribution of the fatty acid metabolism and FFAR1/GPR40 signaling to FFA-induced insulin secretion in the absence of glucose. Human islets were incubated with or without palmitate (PA) (a-d) or oleate (OA) (e-h) for 20 min in the absence of glucose. a and e Representative graphs of dynamic insulin secretion from perifused islets is shown. Fatty acids were added as indicated. $\mathbf{b}, \mathbf{c}, \mathbf{d}, \mathbf{f}, \mathbf{g}$ and $\mathbf{h}$ ) Total, first-phase and second-phase of FFA-stimulated insulin secretion during perifusion was expressed as fold control. Results are means \pm SEM of 3 donors. ${ }^{*} P<0.05$ vs control, $\# P<0.05$ vs fatty acid alone

SFAs and MUFAs on OCR in isolated human islets cultured at fasting glucose concentrations. The higher OCR observed in the presence of MUFAs was due to higher glycolysis. In line with these results, in the absence of glucose, ECAR and OCR were not elevated by the addition of fatty acids. Surprisingly, insulin secretion was induced by fatty acids even in the absence of glucose with MUFAs being stronger than SFAs. One of the potential explanations of stimulating insulin secretion but not metabolism in the absence of glucose is the action of fatty acids via FFAR1/GPR40 signaling. Indeed, inhibition of this pathway in SFA- and MUFA-treated human islets cultured in the absence of glucose reduced insulin secretion to the control level. Presumably, MUFAs have higher capacity to activate FFAR1/GPR40 signaling than SFAs. The differential potency of fatty acids to activate this receptor signaling may also explain higher OCR in the presence of MUFAs at $5.5 \mathrm{mM}$ glucose. It has been demonstrated that receptor signaling affects mitochondrial respiration [9]. It needs to be mentioned that our 
hypothesis is not in line with a previous study where it has been reported that pEC50 values for the elevation of intracellular calcium in HEK293 cells stably expressing FFAR1/GPR40 were not significantly different between MUFAs and SFAs [25]. Reduction of insulin secretion to control level from SFA- and MUFA-treated human islets by triacsin $C$ implies that higher capacity of MUFAs to stimulate insulin secretion might be explained even by its intracellular metabolism. One of the potential mechanisms is a greater capacity of triglyceride esterification $[26,27]$. Higher esterification rate would increase generation of metabolites via the glycerolipid/free fatty acid cycle and, in such way, cause higher secretion of insulin [28]. On the other hand, in the absence of glucose, FFAs would rather be used for oxidation and production of ATP than for esterification [13]. Complete inhibition of fatty acid-induced stimulation of insulin secretion by inhibiting either intracellular metabolism or GPR40/ FFAR1 signaling suggests that these pathways are interrelated and act synergistically. Interestingly, whereas OCR was reduced by approximately $10 \%$ in islets incubated in the absence of glucose, insulin secretion was lowered by almost $60 \%$. It seems that beta-cells may efficiently use different sources for ATP generation and, thereby, maintaining normal cell function. However, to efficiently enhance insulin secretion glucose is required.

\section{Conclusions}

In conclusion, we found that short-term exposure of human islets to long-chain FFAs induced insulin secretion at physiologically fasting blood glucose levels, with MUFAs being more powerful than SFAs. These effects were partly due to increased glycolytic flux and mitochondrial respiration and partly due to mitochondriaindependent effects via fatty acid metabolism and FFAR1/GPR40 signaling. Our results imply that stimulatory effects of fatty acids on insulin secretion at fasting glucose concentrations may contribute to hyperinsulinemia in subjects with elevated levels of FFAs.

\footnotetext{
Acknowledgements

We thank the Nordic Network for Clinical Islet Transplantation, supported by the Swedish national strategic research initiative EXODIAB (Excellence of Diabetes Research in Sweden) and the JDRF (Juvenile Diabetes Research Foundation) for supply of human islets (JDRF Award 31-2008-413 and the European Consortium for Islet Transplantation (ECIT)/Islet for Basic Research Program.
}

\section{Funding}

This work was supported by the European Commission FP7 Project Beat-Judo (grant number 279 153), Swedish Diabetes Association (grant number DIA 2013-043), Family Ernfors Foundation (grant number 150 430).

\section{Availability of data and material}

All datasets on which the conclusions of the manuscript rely is presented in the main paper.

\section{Authors' contributions}

$J C$ and ER designed the study, performed the experiments and drafted the manuscript. PB designed the study and revised the manuscript. All authors read and approved the final manuscript.

\section{Competing interests}

The authors declare that they have no competing interests.

\section{Ethics approval and consent to participate}

Ethical permission to use human islets isolated from human donors has been obtained from the "Regional Ethical Review Board in Uppsala" (EPN number 2010/006; 2010-02-10).

Received: 4 February 2016 Accepted: 19 August 2016

Published online: 30 August 2016

\section{References}

1. Yaney GC, Corkey BE. Fatty acid metabolism and insulin secretion in pancreatic beta cells. Diabetologia. 2003;46:1297-312.

2. Stein DT, Stevenson BE, Chester MW, Basit M, Daniels MB, Turley SD, McGarry JD. The insulinotropic potency of fatty acids is influenced profoundly by their chain length and degree of saturation. J Clin Invest. 1997;100:398-403.

3. Warnotte $C$, Nenquin $M$, Henquin JC. Unbound rather than total concentration and saturation rather than unsaturation determine the potency of fatty acids on insulin secretion. Mol Cell Endocrinol. 1999;153: 147-53.

4. Malaisse WJ, Malaisse-Lagae F, Sener A, Hellerstrom C. Participation of endogenous fatty acids in the secretory activity of the pancreatic B-cell. Biochem J. 1985;227:995-1002.

5. Warnotte C, Gilon P, Nenquin M, Henquin JC. Mechanisms of the stimulation of insulin release by saturated fatty acids. A study of palmitate effects in mouse beta-cells. Diabetes. 1994;43:703-11.

6. Hamilton JA, Kamp F. How are free fatty acids transported in membranes? Is it by proteins or by free diffusion through the lipids? Diabetes. 1999;48: 2255-69.

7. Kristinsson H, Smith DM, Bergsten P, Sargsyan E. FFAR1 is involved in both the acute and chronic effects of palmitate on insulin secretion. Endocrinology. 2013;154:4078-88.

8. Itoh Y, Kawamata Y, Harada M, Kobayashi M, Fujii R, Fukusumi S, Ogi K, Hosoya $M$, Tanaka $Y$, Uejima $H$, et al. Free fatty acids regulate insulin secretion from pancreatic beta cells through GPR40. Nature. 2003;422:173-6.

9. Kristinsson H, Bergsten P, Sargsyan E. Free fatty acid receptor 1 (FFAR1/ GPR40) signaling affects insulin secretion by enhancing mitochondrial respiration during palmitate exposure. Biochim Biophys Acta. 1853;2015: 3248-57.

10. Sabin MA, De Hora M, Holly JM, Hunt LP, Ford AL, Williams SR, Baker JS, Retallick CJ, Crowne EC, Shield JP. Fasting nonesterified fatty acid profiles in childhood and their relationship with adiposity, insulin sensitivity, and lipid levels. Pediatrics. 2007;120:1426-33.

11. Rise P, Eligini S, Ghezzi S, Colli S, Galli C. Fatty acid composition of plasma, blood cells and whole blood: relevance for the assessment of the fatty acid status in humans. Prostaglandins Leukot Essent Fatty Acids. 2007;76:363-9.

12. Singer P, Godicke W, Voigt S, Hajdu I, Weiss M. Postprandial hyperinsulinemia in patients with mild essential hypertension. Hypertension. 1985;7:182-6.

13. Prentki M, Matschinsky FM, Madiraju SR. Metabolic signaling in fuel-induced insulin secretion. Cell Metab. 2013;18:162-85.

14. Berne $C$. The metabolism of lipids in mouse pancreatic islets. The oxidation of fatty acids and ketone bodies. Biochem J. 1975;152:661-6.

15. Corkey BE, Deeney JT, Yaney GC, Tornheim K, Prentki M. The role of longchain fatty acyl-CoA esters in beta-cell signal transduction. J Nutr. 2000;130: 299-304.

16. Gravena C, Mathias PC, Ashcroft SJ. Acute effects of fatty acids on insulin secretion from rat and human islets of Langerhans. J Endocrinol. 2002;173: 73-80.

17. Opara EC, Garfinkel M, Hubbard VS, Burch WM, Akwari OE. Effect of fatty acids on insulin release: role of chain length and degree of unsaturation Am J Physiol. 1994;266:635-9. 
18. Littman ED, Pitchumoni S, Garfinkel MR, Opara EC. Role of protein kinase C isoenzymes in fatty acid stimulation of insulin secretion. Pancreas. 2000;20: 256-63.

19. Thorn K, Bergsten P. Fatty acid-induced oxidation and triglyceride formation is higher in insulin-producing MIN6 cells exposed to oleate compared to palmitate. J Cell Biochem. 2010;111:497-507.

20. Bergsten P. Slow and fast oscillations of cytoplasmic $\mathrm{Ca} 2+$ in pancreatic islets correspond to pulsatile insulin release. Am J Physiol. 1995;268:282-7.

21. Bergsten $P$, Hellman B. Glucose-induced amplitude regulation of pulsatile insulin secretion from individual pancreatic islets. Diabetes. 1993;42:670-4.

22. Wikstrom JD, Sereda SB, Stiles L, Elorza A, Allister EM, Neilson A, Ferrick DA, Wheeler MB, Shirihai OS. A novel high-throughput assay for islet respiration reveals uncoupling of rodent and human islets. PLoS One 2012; doi: 10. 1371/journal.pone.0033023.

23. Court JM, Dunlop ME, Leonard RF. High-frequency oscillation of blood free fatty acid levels in man. J Appl Physiol. 1971;31:345-7.

24. Maechler P. Mitochondrial function and insulin secretion. Mol Cell Endocrinol. 2013;379:12-8.

25. Briscoe CP, Tadayyon M, Andrews JL, Benson WG, Chambers JK, Eilert MM, Ellis C, Elshourbagy NA, Goetz AS, Minnick DT, et al. The orphan G proteincoupled receptor GPR40 is activated by medium and long chain fatty acids. J Biol Chem. 2003;278:11303-11.

26. Hollenberg $\mathrm{CH}$, Angel A. Relation of fatty acid structure to release and esterification of free fatty acids. Am J Physiol. 1963;205:909-12.

27. Donabedian RK, Karmen A. Fatty acid transport and incorporation into human erythrocytes in vitro. J Clin Invest. 1967:46:1017-27.

28. El-Azzouny M, Evans CR, Treutelaar MK, Kennedy RT, Burant CF. Increased glucose metabolism and glycerolipid formation by fatty acids and GPR40 receptor signaling underlies the fatty acid potentiation of insulin secretion. $J$ Biol Chem. 2014;289:13575-88.

\section{Submit your next manuscript to BioMed Central and we will help you at every step:}

- We accept pre-submission inquiries

- Our selector tool helps you to find the most relevant journal

- We provide round the clock customer support

- Convenient online submission

- Thorough peer review

- Inclusion in PubMed and all major indexing services

- Maximum visibility for your research

Submit your manuscript at www.biomedcentral.com/submit

C Biomed Central 